(C) 2020 IEEE. Personal use of this material is permitted. Permission from IEEE must be obtained for all other uses, in any current or future media, including reprinting/republishing this material for advertising or promotional purposes, creating new collective works, for resale or redistribution to servers or lists, or reuse of any copyrighted component of this work in other works.

\title{
Industry 4.0 Implementation Challenges and Opportunities: A Managerial Perspective
}

\author{
Bojana Bajic ${ }^{(0)}$, Aleksandar Rikalovic ${ }^{\circledR}$, Nikola Suzic ${ }^{(1)}$, and Vincenzo Piuri ${ }^{\circledR}$, Fellow, IEEE
}

\begin{abstract}
Industry 4.0 is a concept aimed at achieving the integration of physical parts of the manufacturing process (i.e., complex machinery, various devices, and sensors) and cyber parts (i.e., advanced software) via networks and driven by Industry 4.0 technology categories used for prediction, control, maintenance, and integration of manufacturing processes. Industry 4.0, which is expected to have a great impact on manufacturing systems in the future, is attracting attention in both industry and academia. Although academic research on Industry 4.0 is growing exponentially, evidence of Industry 4.0 implementation in practice is still scarce. Moreover, the challenges industry faces when implementing the Industry 4.0 concept seem to be even less addressed. At the start of the present survey, a preliminary literature review identified a lack of comprehensive analysis of the Industry 4.0 implementation challenges. Thus, the purpose of the present article is to provide an overview of the reported Industry 4.0 implementation challenges in the relevant literature by conducting a systematic literature review. Specifically, while the present study differentiates between managerial and technological Industry 4.0 implementation challenges, the focus of the present article is on the managerial Industry 4.0 implementation challenges. This overview is performed by deriving an inductively coded Industry 4.0 technology framework that classifies Industry 4.0 technologies into ten categories: cyber physical systems, Internet of Things, big data analytics, cloud computing, fog and edge computing, augmented and virtual reality, robotics, cyber security, semantic web technologies, and additive manufacturing. The present article identifies, codes, and defines the managerial Industry 4.0 implementation challenges and derives opportunities for overcoming them.
\end{abstract}

Index Terms-Big data analytics (BDA), cyber physical systems (CPS), Industry 4.0, Internet of Things (IoT), managerial implementation challenges, manufacturing, systematic literature review.

\section{INTRODUCTION}

$\mathbf{R}$ ECENTLY, the fourth-industrial revolution, Industry 4.0, has become one of the main topics of research and

Manuscript received September 25, 2019; revised February 28, 2020 and July 30, 2020; accepted September 5, 2020. This work was supported in part by the University of Padova through "Developing and testing Industry 4.0 Mass Customization Implementation Guidelines for SMEs" grant, and in part by the EC within the H2020 Program under Grant 825333 MOSAICrOWN. (Corresponding author: Aleksandar Rikalovic.)

Bojana Bajic and Aleksandar Rikalovic are with the Department of Industrial Engineering and Management, University of Novi Sad, Novi Sad 21000, Serbia (e-mail: bojana.bajic@uns.ac.rs; a.rikalovic@uns.ac.rs).

Nikola Suzic is with the Department of Management and Engineering, University of Padova, Vicenza 36100, Italy (e-mail: nikola.suzic@unipd.it).

Vincenzo Piuri is with the Department of Computer Science, Università degli Studi di Milano, Milano 26013, Italy (e-mail: vincenzo.piuri@unimi.it).

This article has supplementary downloadable material available at https:// ieeexplore.ieee.org, provided by the authors.

Digital Object Identifier 10.1109/JSYST.2020.3023041 discussion by industry and academia in the field of management and engineering [1], [2]. Simply looking at the number of scientific papers dealing with Industry 4.0, it can be seen that the total number of publications is growing at a high rate. Specifically, when searching the Scopus database with "industr* 4.0" in the title, abstract, or keywords, there were 5986 publications in the period from 2012 to 2018, with almost 39\% of them published in 2018.

Historically, before Industry 4.0, the first three industrial revolutions lasted nearly 200 years. The first industrial revolution, which took place at the end of the seventeenth century, was driven by the emergence of steam engines, water forces, and mechanization. The second industrial revolution was driven by assembly lines and Henry Ford's introduction of mass production. The third industrial revolution was driven by the use of computers and automation in production processes in the 1970s [3]. Finally, the fourth industrial revolution, better known as Industry 4.0, is a concept coined and introduced by the German Federal Government to promote its high-tech strategy at the end of 2011 [4], [5].

Since Industry 4.0 is a new concept, many researchers have attempted to define it. Piccarozzi et al. [6] defined Industry 4.0 based on business strategy and from a managerial viewpoint. Other researchers [2], [3], [7] defined this concept based on interconnected technologies that are used in implementing Industry 4.0.

Thus, the definition of the Industry 4.0 concept is not selfevident, and we argue that it also depends on the researchers' viewpoint and their research field. Notably, in the present research, we decided to focus on industry and specifically on the Industry 4.0 implementation challenges in manufacturing. Thus, the following comprehensive Industry 4.0 definition has been derived based on the cited references, as well as on the results inductively generated during the present research (e.g., the list of Industry 4.0 technology categories). Industry 4.0 is a concept aimed at integrating the physical parts of the manufacturing process (i.e. complex machinery, various devices, and sensors) [2] and cyber parts (i.e., advanced software), via networks [8]-[11] and driven by Industry 4.0 technology categories used for prediction, control, maintenance, and integration of manufacturing processes [12], where these technology categories are: cyber physical systems (CPS), Internet of Things (IoT), big data analytics (BDA), cloud computing, fog and edge computing, augmented and virtual reality (AR/VR), robotics, cyber security, semantic web technologies, and additive manufacturing (AM). 
Although the Industry 4.0 concept is in the hype and is expected to lead to worldwide change in manufacturing [13], evidence of Industry 4.0 implementation in practice is scarce. Notably, we can argue that Industry 4.0 is still in the "blue sky" solution phase, with academic literature focusing on the concept but providing scarce evidence of its implementation in practice. Moreover, the reports of Industry 4.0 implementation are usually restricted to pilot studies that have limited effects on the whole company.

This lag in reporting Industry 4.0 implementation is even greater when we consider the reporting of difficulties that companies have with implementing Industry 4.0 in practice. In the present article, we call these difficulties Industry 4.0 implementation challenges. Since these implementation challenges are preventing larger scale Industry 4.0 implementation, we also argue that it becomes crucial to focus research efforts on the various Industry 4.0 implementation challenges that companies face. We further define Industry 4.0 implementation challenges as barriers, problems, obstacles, or issues that appear (or are expected to appear) in the Industry 4.0 implementation process in manufacturing companies.

A preliminary literature review showed that a comprehensive analysis of the Industry 4.0 implementation challenges does not exist, even though there is an unspoken agreement between researchers and practitioners that implementation challenges do exist. Moreover, most of the existing literature still refers to "blue sky" solutions that were written in 2011. This lack of critical observation of the problems that companies are facing when implementing Industry 4.0 is the main motivation for conducting the present research.

Thus, this article attempts to fill this gap in the literature by providing a comprehensive overview of Industry 4.0 implementation challenges. It does so through an inductive systematic literature review of the relevant papers that report Industry 4.0 implementation challenges. Notably, the analysis showed that Industry 4.0 implementation challenges can be divided into managerial and technological challenges (see Section IV for definitions). Due to a need to focus the research presentation, this article is focused on managerial Industry 4.0 implementation challenges. Thus, the research is split into two parts. The second part of the research that is yet to be performed and published will focus on the analysis of technological Industry 4.0 implementation challenges that we identified in the analyzed literature. In the present research, managerial implementation challenges are identified, coded, and defined, and the opportunities for overcoming them in the future are provided (see Tables IV and V). However, the detailed description of possible solutions for identified challenges is outside the scope of this survey and will be included in future planned research activities.

The rest of the article is organized as follows. Section II provides a theoretical background by defining the technology categories of Industry 4.0. Section III presents the systematic literature review method, providing details on the search and selection strategy. Section IV presents the results of the Industry 4.0 managerial implementation challenges analysis performed on the relevant articles. Section V discusses managerial implementation challenges by providing opportunities for overcoming them. Finally, Section VI derives some conclusions and summarizes the paper's contributions.

\section{TECHNOLOGY CATEGORIES FOR INDUSTRY 4.0}

In this section, we provide definitions of the Industry 4.0 technology categories. Notably, these technology categories were generated while conducting the present research. Therefore, we define Industry 4.0 technology categories as follows.

- Cyber Physical Systems represent the systems in which physical objects and software are closely integrated, enabling enhanced interaction (i.e., information exchange) among different components in a myriad of ways [14], [15].

- The Internet of Things represents a network that provides communication between "things" (i.e., objects or devices) [16] by using sensors via information and communication technology infrastructure [16], [17], which results in realtime sensing and actuating abilities [2].

- Big Data Analytics represents a practice for revealing hidden information among massive quantities of data (e.g., big datasets), collected from various devices, using advanced analytical techniques (e.g., data mining, statistical analysis, and predictive analytics) [17], [18], which provides real-time decision making [2].

- Cloud Computing represents a computing service that provides data storage, sharing and processing through visualized and scalable resources over the Internet [19].

- Fog and Edge Computing represent decentralized computing services for storage, processing and applications that take place on the edges of a network. These services act as a middle layer between end users and cloud data centers, effectively reducing the distance that data must travel on the network and producing minimal delays [20]-[24].

- Augmented Reality and Virtual Reality represent the information technologies that provide an indirect experience by creating a virtual space that interacts with human sensory systems (VR) [25] and enable visualization of computer graphics placed in the real environment (AR), providing human interaction with virtual space [26].

- Robotics represents a system that uses industrial robots and/or robotic devices, which are autonomous, flexible, and cooperative, for industrial automation with the goal of performing production tasks more precisely with minimal human involvement [2], [13], [27].

- Cyber Security represents "the set of technologies and processes designed to protect computers, networks, programs, and data from attack, unauthorized access, change, or destruction" [28].

- Semantic Web Technologies, as an extension of the current web, represent the collaborative movement and the set of standards [29] in which information is given a well-defined meaning, better enabling computers and people to work in cooperation [30].

- Additive Manufacturing represents the process of object fabrication by joining materials layer-by-layer (as opposed to subtractive manufacturing technologies) based on digital information, enabling three-dimensional objects to be produced on demand [31]-[34]. 
Search and selection phases

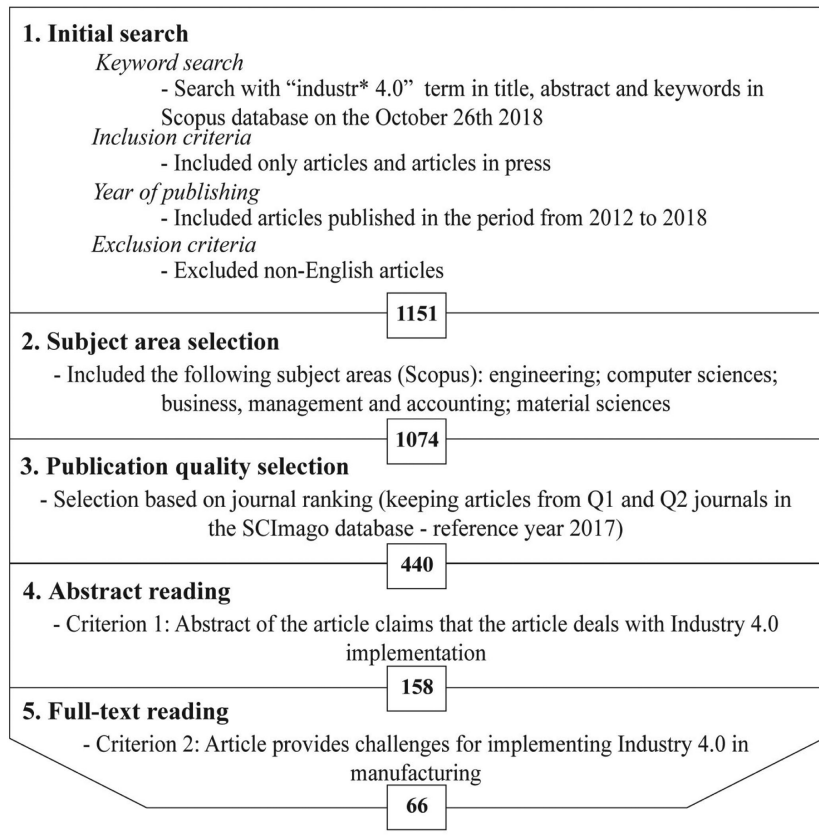

Fig. 1. Article search and selections phases (based on [35] and [36]).

\section{Method—Systematic Literature ReVIEW}

In the present research, we conducted a systematic review of the Industry 4.0 academic literature to analyze the available Industry 4.0 implementation challenges. The research was conducted after a preliminary review of the literature showed that there is no research dealing comprehensively with the challenges of Industry 4.0 implementation in manufacturing companies. The search for relevant publications was performed in the Scopus scientific database ending on October 26, 2018.

The systematic review of the literature included five search and selection phases based on the systematic literature review method from Suzic et al. [35], [36], see Fig. 1. The first phase was the initial search, which comprised four parts: first, the search term "industr* 4.0" was used to search article titles, abstracts, and keywords in the Scopus database; second, only articles and articles in press were left in the search; third, the publications published prior to 2012 were excluded (since the term "Industry 4.0" first appeared in November 2011); and finally, all non-English publications were excluded. As a result, the initial search yielded 1151 hits.

In the second phase, the articles were selected according to the subject area (see Fig. 1). According to the research scope, the subject area should be manufacturing related. As a result, the articles from the following subject areas were left in the selection: engineering; computer sciences; business, management and accounting; and material sciences. As a result, 1074 articles were left in the selection.

In the third phase, the selection of articles was conducted based on their journal ranking (see Fig. 1). Thus, 440 articles published in the journals from Q1 and Q2 quartile journal rankings of the SCImago database (based on 2017 as the reference year) were retained in the selection.
In the fourth phase, the abstracts of all 440 articles were read, and Criterion 1 for selection was applied-Fig. 1 (i.e., "abstract of the article claims that the article deals with Industry 4.0 implementation"). After the abstract reading, 158 articles remained in the selection.

Finally, in the fifth phase, by applying Criterion 2 through full-text reading, the selection was narrowed to 66 relevant articles (see Fig. 1). Criterion 2 was set to select the articles that provided indications of Industry 4.0 implementation challenges (i.e., "article provides challenges for implementing Industry 4.0 in manufacturing").

\section{RESUlTS-INDUSTRY 4.0 IMPLEMENTATION CHALLENGES ANALYSIS: A MANAGERIAL VIEWPOINT}

Relevant articles differed significantly in terms of their scope. Specifically, the article either covers a wide scope of Industry 4.0 technologies addressing them superficially [3], [37], or the article's scope is focused on one or a couple of Industry 4.0 technologies [13], [38], [39].

Since we did not find a suitable framework for the Industry 4.0 implementation challenges analysis, we decided to inductively derive the framework [35], [36] based on our literature review. As a result, the present research derived a framework of Industry 4.0 technology categories for which implementation challenges were recorded in the relevant articles. The analysis showed that the main Industry 4.0 technology categories found in the relevant articles are as follows: CPS, IoT, BDA, cloud computing, fog and edge computing, AR/VR, robotics, cyber security, semantic web technologies, and AM.

These technology categories present the basis of our inductively derived framework for Industry 4.0 implementation challenges analysis.

The analysis of the relevant articles showed that there are two types of Industry 4.0 implementation challenges:

- Managerial Industry 4.0 implementation challenges-are challenges that refer to managerial issues in implementing Industry 4.0. For example, these challenges can be a lack of financial resources, lack of human resources, security issues, and so on. Managerial challenges can be related to either the overall implementation of the Industry 4.0 concept or the implementation of the defined Industry 4.0 technology category.

- Technological Industry 4.0 implementation challengesare challenges that refer to specific technological issues in the implementation of Industry 4.0. For example, these challenges can be related to device incompatibility, data analysis, algorithm development, and so on. Technological challenges are, by their nature, related to the implementation of a specific technology category.

Each of the relevant articles can contain more than one implementation challenge. As a result, the analysis of the relevant articles recorded 55 managerial Industry 4.0 implementation challenges: 23 implementation challenges for Industry 4.0 overall implementation (recorded 40 times in the relevant articlesTable II) and 32 implementation challenges for defined Industry 4.0 technology category implementation (recorded 35 times in 


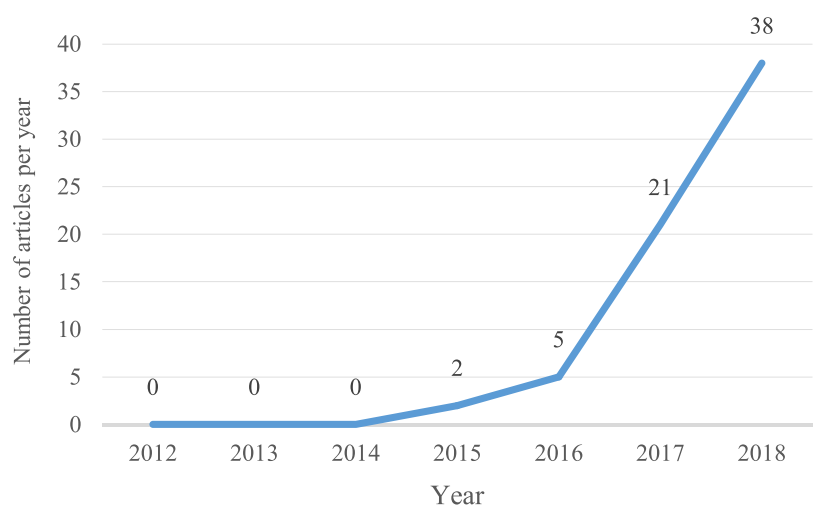

Fig. 2. Number of articles that reported Industry 4.0 implementation challenges per year.

the relevant articles-Table III). Notably, managerial Industry 4.0 implementation challenges were recorded in 28 out of 66 relevant articles. ${ }^{1}$

\section{A. Trends in Industry 4.0 Implementation Challenges Reporting}

This section presents recorded trends in Industry $4.0 \mathrm{im}-$ plementation challenges reported in the literature. An analysis was conducted to provide a comprehensive overview of present state-of-the-art of Industry 4.0 implementation challenges in relevant articles. The trends are as follows.

The earliest reported Industry 4.0 implementation challenges are recorded in the literature in 2015-thus, there was a fouryear-long vacuum in reporting the challenges after the Industry 4.0 term was coined in 2011.

Most of the articles that reported implementation challenges are recorded in 2018-The analysis shows that the greatest number of articles containing Industry 4.0 implementation challenges (i.e., 38 out of 66) was published in 2018 (see Fig. 2). Interestingly, this was 19 times more than in 2015, which implies exponential growth in implementation challenges reporting.

The authors that reported most of the implementation challenges are from China-The analysis shows that China is the country reporting the greatest number of managerial and technological Industry 4.0 implementation challenges (nine articles), followed by the USA and Italy (four articles each). Notably, there is scientific cooperation in this research field between China and the USA, where there are four jointly written articles addressing the Industry 4.0 implementation challenges.

The IEEE Access Journal is the journal that published most of the articles reporting implementation challenges - the total number of journals that published the articles reporting the managerial and technological Industry 4.0 implementation challenges was 37 . The journals which published most of the articles reporting challenges are: the IEEE Access Journal, accounting for eight articles, the International Journal of Computer

\footnotetext{
${ }^{1}$ Note: The 28 relevant articles reporting managerial Industry 4.0 implementation challenges and analyzed in the present article are the following: [3], [5], [13], [37]-[61].
}

TABLE I

NUMBER OF REPORTED MANAGERIAL IMPLEMENTATION CHALLENGES PER ARTICLE

\begin{tabular}{cc}
\hline $\begin{array}{c}\text { Number of reported challenges per } \\
\text { article }\end{array}$ & $\begin{array}{c}\text { Number of articles that report } \\
\text { the challenges }\end{array}$ \\
\hline 1 challenge & 12 \\
2 challenges & 7 \\
3 challenges & 3 \\
4 challenges & 2 \\
5 challenges & 1 \\
6 challenges & 0 \\
7 challenges & 0 \\
8 challenges & 1 \\
9 challenges & 1 \\
10 challenges & 1 \\
\hline \hline
\end{tabular}

Integrated Manufacturing (five articles), Computers in Industry (four articles), and the International Journal of Advanced Manufacturing Technology (four articles). Specifically, the IEEE Access Journal and the International Journal of Advanced Manufacturing Technology accounted for three articles each reporting managerial Industry 4.0 implementation challenges.

The most frequently addressed managerial implementation challenges are related to $B D A$ - The managerial implementation challenges that refer to BDA are reported in five relevant articles.

Most of the relevant articles reported only one managerial implementation challenge-Notably, a relevant article can report more than one managerial implementation challenge. Specifically, Table I shows the most of the relevant articles reporting one (12 articles) or two managerial implementation challenges (7 articles).

The number of reported managerial implementation challenges is increasing each year-The analysis of managerial implementation challenges for Industry 4.0 showed that both challenges for the overall implementation and challenges for defined technology categories were not reported until 2015 (see Fig. 3). Moreover, in 2018, the trend of reporting managerial implementation challenges increased drastically (see Fig. 3). Noticeably, in 2018, the number of overall implementation challenges was larger one-half than the number of implementation challenges for defined technology category implementation (see Fig. 3).

\section{B. Managerial Industry 4.0 Implementation Challenges Analysis}

This section provides the results of the analysis of managerial Industry 4.0 implementation challenges. Managerial Industry 4.0 implementation challenges can be 1) implementation challenges regarding Industry 4.0 overall implementation (see Table II) or 2) implementation challenges for defined Industry 4.0 technology category implementation (see Table III). Both types of managerial implementation challenges are analyzed in detail in this subsection. 


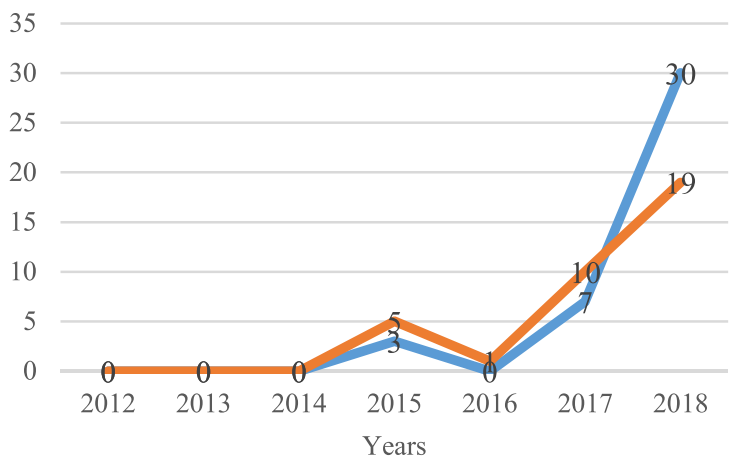

Managerial challenges for overall Industry 4.0 implementation

Managerial challenges for defined technology category implementation

Fig. 3. Number of reported managerial Industry 4.0 implementation challenges per year divided into (a) managerial challenges for overall Industry 4.0 implementation and (b) managerial challenges for defined technology category implementation.

TABLE II

MANAGERIAL INDUSTRY 4.0 IMPLEMENTATION CHALLENGES FOR OVERALL IMPLEMENTATION RECORDED IN THE RELEVANT ARTICLES

\begin{tabular}{lc}
\hline \hline $\begin{array}{c}\text { Groups of managerial Industry 4.0 } \\
\text { implementation challenges for overall } \\
\text { implementation }\end{array}$ & $\begin{array}{c}\text { Frequency of the } \\
\text { challenge groups in the } \\
\text { relevant articles }\end{array}$ \\
\hline Technology challenges & 10 \\
Data challenges & 6 \\
Human resource challenges & 5 \\
Security challenges & 5 \\
Financial resource challenges & 5 \\
Manufacturing system challenges & 4 \\
Standardization challenges & 2 \\
Communication challenges & 1 \\
Strategy challenges & 1 \\
Environmental challenges & Total
\end{tabular}

1) Managerial Implementation Challenges for Industry 4.0 Overall Implementation: Analysis of the managerial implementation challenges for Industry 4.0 overall implementation yielded 23 distinct challenges reported 40 times in the relevant articles (see Table II). These 23 challenges are grouped into 10 groups that appeared with different frequencies in the relevant articles (see Table II). Further on, these implementation challenges are reported in detail in this subsection.

Technology challenges (related to technology management issues, operations management issues, etc.) are recorded ten times in the relevant articles (see Table II). The technology challenges appear in the form of the following.

- Lack of technology maturity [3], [38], [40]—meaning that the relevant literature determines the majority of existing

TABLE III

MANAGERIAL INDUSTRY 4.0 IMPLEMENTATION CHALLENGES FOR DEFINED TECHNOLOGY CATEGORY RECORDED IN THE RELEVANT ARTICLES

\begin{tabular}{c}
\hline $\begin{array}{c}\text { Industry } 4.0 \text { technology } \\
\text { category/categories }\end{array}$ \\
\hline CPS \\
\hline
\end{tabular}

IoT

BDA

\begin{tabular}{c}
\hline Cloud Computing \\
\hline $\begin{array}{c}\text { Fog/Edge } \\
\text { Computing }\end{array}$ \\
\hline AR/VR
\end{tabular}

$\mathrm{AM}$

IoT, AM

IoT, BDA and

Robotics

CPS, IoT, Cloud Computing

CPS, IoT, BDA, Cloud Computing
Implementation challenges for Industry 4.0 defined technology category implementation

The need for large investments in CPS technology with uncertain returns on investments The need for large investments in employee training courses for using the CPS technology Lack of manufacturing system integration An insufficient level of technological intelligence

Difficulties in the shop-floor installation of IoT technology

Resistance to adopting new technology due to the need for large investments

The need for a backup plan for IoT implementation

The lack of human resources

The inability to develop BDA algorithms

The need for large investments in data storage

Organizational challenges

The insufficient knowledge about data variation requirements

The inability to integrate and synchronize databases

The inability to achieve real-time maintenance

The unreliability of actions taken on the basis of obtained analytics

The unreliability of storing data in one central location

The financial feasibility regarding company size

The unprofitable data kept in a limited storage space

Legislation challenges

The lack of information system standards

The need for developing a backup implementation plan

Insufficiently developed technology level

The lack of manufacturing system integration using fog/edge computing technologies

The lack of manufacturing system integration using AR/VR technologies

The lack of skilled workers for AM processes

Excessive investments in $\mathrm{AM}$ equipment

The lack of manufacturing system integration in the joint integration of IoT and AM

The inability to produce mass-customized products

Legislation restrictions for robotics in the joint integration of IoT, BDA and robotics

The lack of financial resources for the joint implementation of the CPS, IoT and cloud computing

Obstacles for data collection in the joint implementation of CPS, IoT, BDA and cloud computing

The need for technology improvement in the joint implementation of CPS, IoT, BDA and cloud computing 
technologies as not mature enough to satisfy the requirements for the highly complex implementation of Industry 4.0 in practice.

- Lack of manufacturing system integration [3], [5], [13], [38], [40] — which implies that the intricacy in the integration of different technologies results in the lack of vertical and horizontal integration of the entire manufacturing system.

- Company's unawareness of existing Industry 4.0 technologies [37] - which refers to cases when companies are not aware of the existing technologies, for example, some cloud services, online design and simulation software, continuous data storage, and high-performance computing.

- Lack of production system reconfiguration ability [13] specifically, the lack of flexibility in manufacturing companies implies the operational inability to change the production method according to market demands with minimal effort and delay.

Data challenges are recorded six times in the relevant articles (see Table II). The data challenges appear in the form of the following.

- The inability to extract knowledge from the data [5], [37]meaning that the ability to extract useful information from numerous data sources and to transform the data into a form readable by different machines/devices has not yet been reached.

- The unstructured format of collected data [41] — the unstructured format of collected data from different levels of hierarchical control and multiple data sources leads to an inability to understand the production process in manufacturing companies.

- The massive data to manage, store, and process [37]—refers to the need of manufacturing companies to manage, store, and process a massive quantity of unstructured data without the support of adequate technology that can handle that quantity of data at once.

- Insufficient quality of the collected data [5]—which is reflected in the fact that the data collected in the manufacturing companies are often irrelevant, redundant, noisy, or unreliable.

- Insufficient data processing power [41]—which is related to the company's need to have a real-time response and predictive maintenance of the manufacturing system. Accordingly, the processing of rapidly generated heterogeneous big data becomes a challenge for traditional tools and existing technologies that have been used in a similar way for a long period of time and have become embedded as traditional manufacturing processes.

Human resource challenges are recorded five times in the relevant articles (see Table II). The human resources challenges appear in the form of the following.

- Lack of Industry 4.0 skilled workers [13], [42], [43]— which refers to Industry 4.0 companies' need for employees who possess multidisciplinary skills in informatics, mathematics, management, data analytics, and engineering.

- Lack of workers with a clear vision and commitment to Industry 4.0 implementation [40]—which refers to the deficiency of highly educated workers who have a vision about the benefits of Industry 4.0 and are open-minded in regard to the implementation of new advanced technologies in manufacturing companies.

- Workers' resistance to knowledge upgrades [38] - the upgrade of workers' knowledge is one of the basic requirements for Industry 4.0 implementation. However, the resistance of workers to change and upgrading their knowledge can stop the company from starting/continuing with the Industry 4.0 implementation process.

Security challenges are recorded five times in the relevant articles (see Table II). The security challenges appear in the form of the following.

- Manufacturing companies' low level of trust with second parties [37], [44] — which refers to the fact that most manufacturing companies are not willing to share or exchange information and knowledge with second parties (i.e., other companies, consultants, and universities) due to companies' policies and security controls.

- Insecure connectivity protocols [13]—which refer to the need for real-time communication to have secure connectivity without obstruction by using different protocols among manufacturing companies.

- The need for data protection [3], [13]—which is related to the need of the manufacturing companies to secure the protection of their confidential data.

Financial resource challenges are recorded five times in the relevant articles (see Table II). The financial resources challenges appear in the form of the following.

- The need for large investments in new technology [3], [13], [43], [44] — which refers to a need to invest substantial financial resources, which in turn divert companies from considering the implementation of new technologies.

- The uncertain returns on investments [37]—which refers to the company's perceived risk that the implementation of emerging technologies will not improve manufacturing processes in the way companies have imagined and will not return the investment.

Manufacturing system challenges are recorded four times in the relevant articles (see Table II). The manufacturing system challenges appear in the form of the following.

- Insufficiently developed manufacturing system infrastructures [13], [37], [38]— which refers to insufficiently developed or nonexistent information and technological infrastructure of the manufacturing system that hinder the integration of manufacturing companies and their processes.

- High manufacturing system complexity [45]—refers to the inability of the company to manage its manufacturing system as a consequence of the implementation of the complex information and technological infrastructures needed for Industry 4.0.

Standardization challenges are recorded two times in the relevant articles (see Table II). The standardization challenges appear in the form of the following.

- Difficulties in establishing uniform standards for information exchange [37], [44]—with the Industry 4.0 concept still being vague to many companies, the establishment of standards for information exchange in manufacturing 
companies remains a challenge, mainly due to inability to reach an agreement on uniform standards. Consequently, this nonexistence of uniform standards results in the inability to share or exchange information and knowledge generated on different platforms.

Communication challenges are recorded once in the relevant articles (see Table II). The communication challenges appear in the form of the following.

- Lack of Internet connectivity [37]—which refers to the companies in undeveloped countries having issues with Internet connectivity. Consequently, these connectivity problems affect information sharing and collaboration between manufacturing companies.

Strategy challenges are recorded once in the relevant articles (see Table II), and they appear in the following form.

- Lack of strategy [13] — which refers to the lack of a systematic approach to adopting new Industry 4.0 manufacturing concepts that enable more flexible and dynamic manufacturing.

Environmental challenges are recorded once in the relevant articles (see Table II). The environmental challenges appear in the form of the following.

- The need to prevent potential serious environmental side effects of Industry 4.0 implementation [13]—refers to a need to prevent effects on the environment during Industry 4.0 implementation. For example, the use of automation in manufacturing companies and heavy energy consumption may cause the emission of large quantities of greenhouse gases. Thus, to prevent these effects, companies are challenged to comply with environmental norms during Industry 4.0 implementation.

2) Managerial Implementation Challenges for Industry 4.0 Defined Technology Category Implementation: Analysis of the managerial implementation challenges for Industry 4.0 defined technology category implementation yielded 32 distinct challenges reported 35 times in the relevant articles (see Table III). These 32 challenges are grouped into 11 groups based on the technology category/categories they address (see Table III). Further on, these implementation challenges are reported in detail in this section.

Managerial implementation challenges for CPS are recorded in the form of three distinct implementation challenges in the relevant articles (see Table III). The CPS challenges appear in the form of the following.

- The need for large investments in CPS technology with uncertain returns on investments [46] — which means that CPS technology requires large investments, while at the same time, the return of those investments is dependent on "high product quality, factory throughput, equipment utilization, flexibility, and low energy consumption" and the return is not certain.

- The need for large investments in employee training courses for using the CPS technology [47]—refers to the need to organize employee training courses for use of the CPS technology, which in the end amount to large investments for organizing such training activities.

- Lack of manufacturing system integration [48] —in the case of the CPS technologies implementation is related to the mutual connection and seamless integration between physical and virtual systems and the achievement of interaction in real time.

- An insufficient level of technological intelligence [47]refers to the current level of achieved equipment intelligence that often does not fulfill the requirements of the CPS technologies' implementation.

Managerial implementation challenges for IoT are recorded in the form of three distinct implementation challenges in the relevant articles (see Table III). The IoT challenges appear in the form of the following.

- Difficulties in the shop-floor installation of IoT technology [49] — refers to the installation of new IoT technology aimed at capturing real-time data in manufacturing processes.

- Resistance to adopting new technology due to the need for large investments [50]—refers to the reluctance to apply new IoT technology due to unclear potential benefits while expecting large investments.

- The need for a backup plan for IoT implementation [51] refers to the difficulty in understanding what will happen after IoT implementation, which refers to the need to develop drop-out plans that would enable the company to return the pre-IoT implementation manufacturing settings.

Managerial implementation challenges for BDA are recorded in the form of 14 distinct implementation challenges in the relevant articles (see Table III). The BDA challenges appear in the form of the following.

- The lack of human resources [52], [53] — which refers to the difficulty in finding and keeping reliable employees with a strong vision, commitment to realizing Industry 4.0 concept and strong multidisciplinary skills. These multidisciplinary skills cover engineering, computing, analytics, design, planning, automation, and production.

- The inability to develop BDA algorithms [52], [54]—which refers to the need for the company to possess a cross-domain analytics team capable of creating and designing offline prediction algorithms and early issue detection.

- The need for large investments in data storage [52], [53]which refers to the company's financial resources needed to acquire one central location for data storage (e.g., the cloud).

- Organizational challenges [52]—includes challenges associated with achieving a positive impact on the manufacturing process using BDA technologies and aligning the objectives of analytics with the overall corporate strategy.

- The insufficient knowledge about data variation requirements [52]—includes various requirements (e.g., the format, availability, quality, security, and data acquisition) from different devices for system coordination.

- The inability to integrate and synchronize databases [52]refers to the challenges of synchronization and integration of databases into existing systems in accordance with manufacturing company policies.

- The inability to achieve real-time maintenance [54]—which is related to the company's inability to efficiently achieve real-time active maintenance using big data. 
- The unreliability of actions taken on the basis of obtained analytics [52] —represents the doubt in the validity of the obtained results of the analytics, which stops BDA implementation processes.

- The unreliability of storing data in one central location [52] — which represents the data storing security issues regarding the possibilities of cyber-attacks.

- The financial feasibility regarding company size [52]which refers to the fact that small and medium enterprises (SMEs) usually do not have a sufficient amount of financial resources to invest in BDA technology compared with large enterprises.

- The unprofitable data kept in a limited storage space [52]refers to the data that do not provide any additional value but use storage space. Consequently, the question for the company is whether these data will be needed in the future and, if not, when the data should be deleted.

- Legislation challenges [53]-represent the legal restrictions that may limit companies in the adoption of new technology.

- The lack of information system standards [53]—refers to issues when the policy of the company does not allow for the adoption of certain open information automation network standards, such as the Open Platform Communications server for device communications and the ISA95 for system interoperability.

- The need for developing a backup implementation plan [53] — refers to the need to develop a reserve implementation or drop-out plan in the case that during the implementation process, problems occur with a negative impact on a company's manufacturing performances.

Managerial implementation challenges for cloud computing are recorded in the form of one implementation challenge in the relevant articles (see Table III). The cloud computing challenge appears in the form of the following.

- Insufficiently developed technology level [55]—which is related to technical limitations that constrain the application of advanced technology, e.g., industrial robots due to constrained computing and communication challenges.

Managerial implementation challenges for fog/edge computing are recorded in the form of one implementation challenge in the relevant articles (see Table III). The fog/edge computing challenge appears in the form of the following.

- The lack of manufacturing system integration using fog/edge computing technologies [56]—refers to the issues of system integration linked to the lack of software systems that could be integrated seamlessly due to different data representations by different systems, incompatible interfaces, different communication protocols, and so on.

Managerial implementation challenges for $A R / V R$ are recorded in the form of one implementation challenge in the relevant articles (see Table III). The AR/VR challenge appears in the form of the following.

- The lack of manufacturing system integration using AR/VR technologies [57]—refers to the issues of manufacturing system integration, which include integrating heterogeneous software systems (e.g., ERP-enterprise resource planning, MES - manufacturing execution systems, and QMS - quality management systems) and information exchange across the entire manufacturing system and product lifecycle.

Managerial implementation challenges for AM are recorded in the form of two distinct implementation challenges in the relevant articles (see Table III). The AM challenges appear in the form of the following.

- The lack of skilled workers for AM processes [58]—refers to difficulty of finding the educated/trained workers capable of performing the AM processes.

- Excessive investments in AM equipment [58] - refer to financial investments in AM equipment that companies consider excessive in comparison to the expected return.

Managerial implementation challenges for multiple technology implementation are managerial challenges that refer to the simultaneous implementation of multiple technology categories (see Table III):

- IoT and AM;

- IoT, BDA, and robotics;

- CPS, IoT, and cloud computing;

- CPS, IoT, BDA, and cloud computing.

According to the analysis, five implementation challenges for multiple technology categories are recorded in the relevant articles (see Table III). The multiple technology category challenges appear in the form of the following.

- The lack of manufacturing system integration in the joint integration of IoT and AM [59] — which refers to the difficulty of the company in achieving seamless digital workflow integration of the product lifecycle.

- The inability to produce mass-customized products (IoT, AM) [59] — which refers to the difficulty of the company in developing highly flexible and adaptive manufacturing processes capable of manufacturing customized products with an efficiency comparable to mass production.

- Legislation restrictions for robotics in the joint integration of IoT, BDA, and robotics [60]—which refers to the limited implementation of robots in companies (e.g., autonomous vehicles) due to a lack of regulated legislation that would enable their implementation.

- The lack of financial resources for the joint implementation of the CPS, IoT, and cloud computing [61]—refers to the need to invest substantial financial resources in the implementation of these three technologies, where it should be stressed that the current technological solutions are not affordable for SMEs.

- Obstacles for data collection in the joint implementation of CPS, IoT, BDA, and cloud computing [39]—refers to the high dimensionality, variability in metrics, high noise, and unstructured nature of data acquired from intelligent manufacturing equipment.

- The need for technology improvement in the joint implementation of CPS, IoT, BDA, and cloud computing [39]refers to the need for improvements in the intelligence level of the manufacturing equipment to better respond to problems such as dynamic scheduling and the connection between functions and devices in the manufacturing system. 


\section{DISCUSSION}

The research results reported in the previous section lead to discussion of managerial Industry 4.0 implementation challenges, providing the following:

1) analysis of trends in Industry 4.0 implementation challenges reporting;

2) critical review of the recorded Industry 4.0 managerial implementation challenges;

3) derived opportunities for overcoming managerial Industry 4.0 implementation challenges for overall implementation;

4) derived opportunities for overcoming managerial implementation challenges for Industry 4.0 defined technology category implementation.

\section{A. Analysis of Trends in Industry 4.0 Implementation Challenges Reporting}

Trends in Industry 4.0 implementation challenges reporting identified in the present research provide a specific state-of-theart of the advancement in the implementation of Industry 4.0 in practice. The trends reported in the Results section do this through the analysis of the challenges the industry faces while implementing Industry 4.0. In the current section, implications of these trends are further discussed.

The earliest reported Industry 4.0 implementation challenges are recorded in the literature in 2015-However, the Industry 4.0 concept appeared in 2011. Thus, in the four-year period, the literature did not report any of the Industry 4.0 implementation challenges (see Fig. 2). This vacuum is natural since the concept was completely new for the industry. As a consequence, the implementation challenges started appearing in the literature four years later. Moreover, this lag in challenges reporting fits with the "innovation trigger" period from the Gartner hype cycle [62], where early proof-of-concept stories and interest in the media caused significant publicity for the Industry 4.0 concept.

Most of the articles that reported implementation challenges are recorded in 2018 - The analysis showed that reported managerial Industry 4.0 implementation challenges had exponential growth (see Fig. 2). On the basis of these results, we argue that this trend will continue in the near future. In fact, it can be expected that as more Industry 4.0 implementation is performed, more challenges will be faced by the experts and more of these challenges will be reported in the literature. Furthermore, this exponential growth in implementation challenges reporting corresponds with the hype Industry 4.0 is causing in the industry and academia [2].

The authors that reported most of the implementation challenges are from China-Interestingly, most of the authors reporting the challenges are from China, followed by the USA and Italy. It is somehow understandable that China, as a country that is investing highly in technology and has roughly one-fifth of the world population, is in first place on this list. Nevertheless, a valid question to ask could be why there are not more articles from Germany providing implementation challenges since Industry 4.0 is being popularized by the German government and industry.
The IEEE Access Journal is the journal that published most of the articles reporting implementation challenges-It is not surprising that the IEEE Access Journal was the journal that accounted for the majority of articles reporting the Industry 4.0 implementation challenges. IEEE Access Journal is multidisciplinary (covering computer sciences, engineering, and material sciences) and publishes a variety of article types (i.e., technical articles, applications-oriented and interdisciplinary articles, surveys, and reviews) that cover a wide range of Industry $4.0 \mathrm{im}$ plementation topics. The analysis of the source publications of the articles dealing with Industry 4.0 implementation challenges also showed that most of the journals are engineering journals with a strong focus on computer science and practice (e.g., the IEEE Access Journal, the International Journal of Computer Integrated Manufacturing, Computers in Industry, and the International Journal of Advanced Manufacturing Technology). This trend will probably continue in the future since Industry 4.0 is a strongly technology-oriented concept.

The most frequently addressed managerial implementation challenges are related to $B D A-$ Based on this finding, it could be argued that, for the moment, BDA represents the most significant technological bottleneck for implementation of Industry 4.0 in practice. If this conclusion is correct, then we can expect that in the near future, considerable attention from researchers and industry will be focused on solving implementation challenges related to BDA.

Most of the relevant articles report only one managerial implementation challenge-The analysis showed that when articles reported implementation challenges, most reported only one (see Table I). We could argue that this is due to the focus of the paper but also due to hesitation to report the challenges for some reason. Additionally, it could be argued that the literature is still mainly focused on the positive aspects of Industry 4.0 implementation, along with the created Industry 4.0 hype, neglecting the difficulties of Industry 4.0 implementation to a large extent.

The number of reported managerial implementation challenges is increasing each year-The number of reported managerial implementation challenges grew for both overall implementation challenges and implementation challenges for defined technology category implementation. According to the analysis (see Fig. 3), for 2018, the number of reported challenges for overall implementation was larger by one-half than the number of challenges for a defined technology category implementation. However, with maturation and wider implementation of Industry 4.0 , we can probably expect that in the near future, the number of reported managerial challenges for defined technology category implementation will increase and surpass the reported overall implementation challenges.

\section{B. Critical Review of the Recorded Industry 4.0 Managerial Implementation Challenges}

As stated in the Introduction section, the present research is focused on managerial Industry 4.0 implementation challenges. These challenges articulate either overall issues with Industry 4.0 implementation (e.g., human resources, security, 
and financial resources-Table II) or issues that are connected with a defined Industry 4.0 technology (e.g., CPS, IoT, and BDA-Table III).

Both types of managerial implementation challenges bring specific value to the system designer as the final user of the surveyed research. Thus, the overall challenges help the implementer create a more strategic viewpoint, while the defined technology category challenges provide more specific information regarding the problems with the implementation of the defined technology. Notably, both types of challenges analyzed in the present research refer to the managerial issues of the implementation without going into the specifics of technology implementation. This detailing of the issues of the implementation of specific technologies is outside the scope of the present research. The research on the technological Industry $4.0 \mathrm{im}-$ plementation challenges, which will complement the present research, is underway.

Managerial implementation challenges for Industry 4.0 overall implementation in almost $80 \%$ of the cases focus on technology, data, human resources, security, or financial resources (see Table II). Furthermore, they comprise approximately $60 \%$ of all managerial challenges reported in the present research (see Fig. 1). However, it can be argued that in some cases, these challenges can be seen as too generic for the system designer. This argument will probably depend on the current status of the company implementing Industry 4.0. Thus, a company that is at the beginning of the Industry 4.0 implementation is expected to have a high interest in this type of challenge. We can also expect that a company that has made large advances in implementing Industry 4.0 will have more interest in managerial implementation challenges for defined technology categories and in the technological implementation challenges.

The managerial implementation challenges for the defined technology category are dispersed among seven different single technologies and an additional four groups of technologies (see Table III). Notably, three technology categories dominate the list of these challenges, namely: BDA, CPS, and IoT. Specifically, the most challenges are reported for the BDA (14 distinct challenges-Table III). This implies that the BDA along with the CPS (four challenges) and the IoT (three challenges) is currently the focus of the researchers' and industry attention. Furthermore, this implies that the current work is being performed to address problems in these three technologies that represent, especially the BDA, the bottleneck but also the basis for implementation of other Industry 4.0 technologies.

While the focus of this type of challenges is on BDA, CPS, and IoT, there are some technologies that, on their own, do not report a single challenge (i.e., robotics, cyber security, and semantic web technologies - Table III). The use of these technologies, or the advanced part of these technologies (e.g., use of cobots in robotics), in Industry 4.0 is still evolving. Consequently, we can argue that the challenges are not yet visible to the Industry 4.0 system designers and implementers. Thus, they are not reported yet in the literature, even though they are known in the community to be a challenge. We expect to further complement the understanding of the implementation challenges with the next step of the research focused on the technological implementation challenges.

\section{Deriving Opportunities for Overcoming Managerial Implementation Challenges for Industry 4.0 Overall Implementation}

In the Results section, the managerial Industry 4.0 implementation challenges for overall implementation have been identified, coded, and defined (Section IV-B1). In the present subsection, we build upon the obtained results by deriving opportunities to overcome each of the identified challenges. These opportunities are provided in tabular form to be concise and comprehensive and to avoid redundancy (see Table IV).

Notably, neither Table IV nor Table V provides a detailed description of possible solutions for the identified challenges. This task is outside the scope of this survey. Moreover, a detailed understanding of the causes of the challenges is essential to address them in the specific instance of a system. This understanding needs to be performed by the system designers, considering all characteristics of the specific technologies that the company is using and the specific implementation case.

\section{Deriving Opportunities for Overcoming Managerial Implementation Challenges for Defined Industry 4.0 Technology Category Implementation}

In the Results section, the managerial Industry 4.0 implementation challenges for defined technology category implementation have been identified, coded, and defined (see Section IV-B2). In this subsection, we build upon the obtained results by deriving opportunities to overcome each of the identified challenges. These opportunities are provided in a tabular form to be concise and comprehensive and to avoid redundancy (see Table V).

Notably, for some of the identified Industry 4.0 technology categories, we did not identify managerial implementation challenges in the relevant literature, namely, robotics, cyber security, and semantic web technologies. Interestingly, even though managerial implementation challenges were not separately recorded for robotics, the robotic implementation challenge was recorded for the implementation process of multiple technologies, namely, IoT, BDA, and robotics.

\section{CONCLUSION}

Initial literature sampling revealed that only a minority of the available Industry 4.0 papers deals with the Industry 4.0 implementation challenges while prevalently proposing benefits obtained by Industry 4.0 implementation. Thus, the initial insight was that the current focus of the research literature is on the benefits of Industry 4.0 and not on the challenges that are encountered in the implementation of the concept. Moreover, a comprehensive analysis of the Industry 4.0 implementation challenges was not found in the literature. However, we argue that these implementation challenges are preventing larger-scale Industry 4.0 implementation, and thus, it is crucial to focus research efforts on the various Industry 4.0 implementation challenges companies face.

Consequently, the goal of the present research was set to survey the state-of-the-art of the current trends of the Industry 4.0 implementation challenges, to identify these challenges, define 
TABLE IV

OPPORTUNITIES FOR OVERCOMING MANAGERIAL IMPLEMENTATION CHALLENGES FOR INDUSTRY 4.0 DEFINED TECHNOLOGY CATEGORY/CATEGORIES

\begin{tabular}{|c|c|c|c|}
\hline Challenge group & Challenge & References & Opportunities for overcoming the challenge \\
\hline \multirow{4}{*}{$\begin{array}{l}\text { Technology } \\
\text { challenges }\end{array}$} & Lack of technology maturity & {$[3],[38],[40]$} & $\begin{array}{l}\text { - further develop existing technologies to reach the maturity level needed for } \\
\text { implementing Industry } 4.0 \text { in manufacturing }\end{array}$ \\
\hline & $\begin{array}{l}\text { Lack of manufacturing system } \\
\text { integration }\end{array}$ & $\begin{array}{l}{[3],[5],[13]} \\
{[38],[40]}\end{array}$ & $\begin{array}{l}\text { - integrate the existing manufacturing system before starting the implementation of } \\
\text { Industry } 4.0 \\
\text { - develop technologies compatible with other Industry } 4.0 \text { technologies to avoid } \\
\text { intricacy }\end{array}$ \\
\hline & $\begin{array}{l}\text { Company's unawareness of existing } \\
\text { Industry } 4.0 \text { technologies }\end{array}$ & {$[37]$} & $\begin{array}{l}\text { - establish new company department (or dedicate designated personnel at least) } \\
\text { responsible for monitoring Industry } 4.0 \text { technology } \\
\text { - establish long-term collaboration between industry and institute/university researchers } \\
\text { to maintain insight into Industry } 4.0 \text { technology development }\end{array}$ \\
\hline & $\begin{array}{l}\text { Lack of production system } \\
\text { reconfiguration ability }\end{array}$ & {$[13]$} & $\begin{array}{l}\text { - design/redesign the manufacturing system to become more flexible } \\
\text { - develop/adapt technology that can rapidly change the production process }\end{array}$ \\
\hline \multirow{5}{*}{ Data challenges } & $\begin{array}{l}\text { The inability to extract knowledge } \\
\text { from the data }\end{array}$ & {$[5],[37]$} & $\begin{array}{l}\text { - provide data collected from numerous data sources in a suitable format } \\
\text { - develop algorithms capable of extracting information based on data analysis }\end{array}$ \\
\hline & $\begin{array}{l}\text { The unstructured format of collected } \\
\text { data }\end{array}$ & {$[41]$} & $\begin{array}{l}\text { - standardize the data collection format } \\
\text { - develop algorithms for data interpretation into a defined and standardized format }\end{array}$ \\
\hline & $\begin{array}{l}\text { The massive data to manage, store and } \\
\text { process }\end{array}$ & {$[37]$} & $\begin{array}{l}\text { - invest in technology, namely, servers, processing power and additional storage space } \\
\text { - develop algorithms for data compression and reduction }\end{array}$ \\
\hline & $\begin{array}{l}\text { Insufficient quality of the collected } \\
\text { data }\end{array}$ & {$[5]$} & - invest in more reliable data collection devices and sensors \\
\hline & Insufficient data processing power & {$[41]$} & $\begin{array}{l}\text { - invest in increasing processing power } \\
\text { - increase processing power capable of performing real-time response and predictive } \\
\text { maintenance }\end{array}$ \\
\hline \multirow{3}{*}{$\begin{array}{l}\text { Human resource } \\
\text { challenges }\end{array}$} & Lack of Industry 4.0 skilled workers & {$[13],[42],[43]$} & $\begin{array}{l}\text { - train and create multidisciplinary teams within the company } \\
\text { - teach a new generation of students and researchers about current and future industry } \\
\text { trends with a focus on developing multidisciplinary skills }\end{array}$ \\
\hline & $\begin{array}{l}\text { Lack of workers with a clear vision } \\
\text { and commitment to Industry } 4.0 \\
\text { implementation }\end{array}$ & {$[40]$} & $\begin{array}{l}\text { - provide workers with Industry } 4.0 \text { training that clearly outlines the potential benefits to } \\
\text { the company and workers } \\
\text { - motivate workers to commit to Industry } 4.0 \text { implementation by various incentives and } \\
\text { presentation of Industry } 4.0 \text { concept advantages for the company and workers }\end{array}$ \\
\hline & $\begin{array}{l}\text { Workers' resistance to knowledge } \\
\text { upgrades }\end{array}$ & {$[38]$} & $\begin{array}{l}\text { - motivate workers to adapt new technology in the Industry } 4.0 \text { implementation process } \\
\text { - develop user-friendly devices that ease the transfer from old to new technology for the } \\
\text { workers }\end{array}$ \\
\hline \multirow{3}{*}{$\begin{array}{l}\text { Security } \\
\text { challenges }\end{array}$} & $\begin{array}{l}\text { Manufacturing companies' low level } \\
\text { of trust with second parties }\end{array}$ & {$[37],[44]$} & $\begin{array}{l}\text { - make a contract between companies and second parties that lowers the security } \\
\text { concerns regarding the company data and knowledge protection }\end{array}$ \\
\hline & Insecure connectivity protocols & [13] & $\begin{array}{l}\text { - develop standardized protocols or entire network systems } \\
\text { - implement existing tested standardized protocols or entire network systems }\end{array}$ \\
\hline & The need for data protection & [3], [13] & $\begin{array}{l}\text { - develop secure protocols and networks to stop the cyber-attacks } \\
\text { - develop data storage distributed in multiple locations } \\
\text { - implement existing tested standardized protocols or entire network systems }\end{array}$ \\
\hline \multirow{2}{*}{$\begin{array}{l}\text { Financial } \\
\text { resource } \\
\text { challenges }\end{array}$} & $\begin{array}{l}\text { The need for large investments in new } \\
\text { technology }\end{array}$ & $\begin{array}{l}{[3],[13],[43],} \\
{[44]}\end{array}$ & $\begin{array}{l}\text { - collaborate between industry and academia to apply for international projects to } \\
\text { implement the Industry } 4.0 \text { concept and obtain funding } \\
\text { - establish collaboration between SMEs to invest jointly in new technologies to divide } \\
\text { the technology costs between companies }\end{array}$ \\
\hline & The uncertain returns on investments & {$[37]$} & $\begin{array}{l}\text { - launch Industry } 4.0 \text { pilot projects that do not require large investments in the beginning, } \\
\text { and later invest in tested technology/technologies }\end{array}$ \\
\hline \multirow{2}{*}{$\begin{array}{l}\text { Manufacturing } \\
\text { system challenges }\end{array}$} & $\begin{array}{l}\text { Insufficiently developed } \\
\text { manufacturing system infrastructures }\end{array}$ & [13], [37], [38] & - develop and improve production system infrastructures \\
\hline & $\begin{array}{l}\text { High manufacturing system } \\
\text { complexity }\end{array}$ & {$[45]$} & $\begin{array}{l}\text { - implement only the technologies adequate for the company and avoid introducing } \\
\text { additional complexity to the manufacturing system } \\
\text { - develop algorithms for easier monitoring of complex manufacturing system }\end{array}$ \\
\hline $\begin{array}{l}\text { Standardization } \\
\text { challenges }\end{array}$ & $\begin{array}{l}\text { Difficulties in establishing uniform } \\
\text { standards for information exchange }\end{array}$ & [37], [44] & $\begin{array}{l}\text { - implement uniform standards for information exchange inside the company } \\
\text { - create a uniform standard for information exchange compatible with different } \\
\text { platforms }\end{array}$ \\
\hline $\begin{array}{l}\text { Communication } \\
\text { challenges }\end{array}$ & Lack of Internet connectivity & {$[37]$} & $\begin{array}{l}\text { - install Internet networks in the companies in undeveloped countries } \\
\text { - provide better Internet network signals to locations where companies are located }\end{array}$ \\
\hline $\begin{array}{l}\text { Strategy } \\
\text { challenges }\end{array}$ & Lack of strategy & [13] & $\begin{array}{l}\text { - devise a detailed strategy for Industry } 4.0 \text { concept implementation based on company } \\
\text { requirements and needs }\end{array}$ \\
\hline $\begin{array}{l}\text { Environmental } \\
\text { challenges }\end{array}$ & $\begin{array}{l}\text { The need to prevent potential serious } \\
\text { environmental side effects of Industry } \\
4.0 \text { implementation }\end{array}$ & [13] & - adhere to environmental standards during the implementation of Industry 4.0 \\
\hline
\end{tabular}


TABLE V

OPPORTUNITIES FOR OVERCOMING MANAGERIAL IMPLEMENTATION CHALLENGES FOR INDUSTRY 4.0 DEFINED TECHNOLOGY CATEGORY/CATEGORIES

\begin{tabular}{|c|c|c|c|}
\hline $\begin{array}{l}\text { Technology } \\
\text { category }\end{array}$ & Challenge & References & Opportunities for overcoming the challenge \\
\hline \multirow{4}{*}{$C P S$} & $\begin{array}{l}\text { The need for large investments in CPS } \\
\text { technology with uncertain returns on } \\
\text { investments }\end{array}$ & {$[46]$} & $\begin{array}{l}\text { - establish collaboration between industry and academia which would result in applying for } \\
\text { projects to implement CPS technology to obtain funding }\end{array}$ \\
\hline & $\begin{array}{l}\text { The need for large investments in employee } \\
\text { training courses for using the CPS technology }\end{array}$ & {$[47]$} & $\begin{array}{l}\text { - establish collaboration between industry and academia which would result in applying for } \\
\text { international projects using funding for training courses where the CPS technology would be } \\
\text { applied } \\
\text { - establish long-term collaboration between industry and academia/research centers and create joint } \\
\text { training courses to use of CPS technology }\end{array}$ \\
\hline & Lack of manufacturing system integration & [48] & $\begin{array}{l}\text { - integrate the existing manufacturing system before implementing CPS } \\
\text { - develop CPS technologies compatible with other technologies to achieve seamless integration }\end{array}$ \\
\hline & $\begin{array}{l}\text { An insufficient level of technological } \\
\text { intelligence }\end{array}$ & {$[47]$} & - develop more intelligent equipment that fulfills the requirements of the CPS technologies \\
\hline \multirow{3}{*}{$I o T$} & $\begin{array}{l}\text { Difficulties in the shop-floor installation of IoT } \\
\text { technology }\end{array}$ & [49] & $\begin{array}{l}\text { - develop standards for IoT technology protocols and network for capturing real-time data } \\
\text { - implement standardized IoT technology protocols and networks }\end{array}$ \\
\hline & $\begin{array}{l}\text { Resistance to adopting new technology due to } \\
\text { the need for large investments }\end{array}$ & {$[50]$} & $\begin{array}{l}\text { - develop less expensive IoT technology } \\
\text { - collaborate between companies and academia to apply for international projects to reduce } \\
\text { investment costs in IoT }\end{array}$ \\
\hline & $\begin{array}{l}\text { The need for backup plan for IoT } \\
\text { implementation }\end{array}$ & {$[51]$} & $\begin{array}{l}\text { - develop backup plans that enable the company to roll back to the pre-IoT implementation } \\
\text { manufacturing settings }\end{array}$ \\
\hline \multirow{14}{*}{$B D A$} & The lack of human resources & {$[52],[53]$} & $\begin{array}{l}\text { - train and create multidisciplinary teams with a focus on BDA within the company } \\
\text { - teach a new generation of students and researchers about current and future industry trends with } \\
\text { a focus on developing multidisciplinary BDA skills }\end{array}$ \\
\hline & The inability to develop BDA algorithms & [52], [54] & $\begin{array}{l}\text { - establish a cross-domain analytics team that can create and design off-line prediction algorithms, } \\
\text { and early issues detection }\end{array}$ \\
\hline & The need for large investments in data storage & {$[52],[53]$} & $\begin{array}{l}\text { - develop company capabilities that allow understanding of constant changes in the data storage } \\
\text { market and optimizing the cost of the data storage } \\
\text { - develop algorithms for preprocessing data, namely, for data modification and reduction in the } \\
\text { stored data size }\end{array}$ \\
\hline & Organizational challenges & {$[52]$} & $\begin{array}{l}\text { - establish an analytics team to develop strategies based on data analysis to achieve better } \\
\text { organization within the manufacturing company }\end{array}$ \\
\hline & $\begin{array}{l}\text { The insufficient knowledge about data } \\
\text { variation requirements }\end{array}$ & {$[52]$} & $\begin{array}{l}\text { - introduce standardized requirements for data acquisition, storage, type, for system coordination } \\
\text { inside the company }\end{array}$ \\
\hline & $\begin{array}{l}\text { The inability to integrate and synchronize } \\
\text { databases }\end{array}$ & {$[52]$} & $\begin{array}{l}\text { - change company policies to implement BDA technologies to integrate and synchronize databases } \\
\text { in existing systems }\end{array}$ \\
\hline & The inability to achieve real-time maintenance & {$[54]$} & $\begin{array}{l}\text { - increase company's processing power for faster and more efficient data analysis } \\
\text { - develop algorithms for online analysis after analytical model implementation }\end{array}$ \\
\hline & $\begin{array}{l}\text { The unreliability of actions taken on the basis } \\
\text { of obtained analytics }\end{array}$ & {$[52]$} & - implement pilot projects for testing the developed analytical models \\
\hline & $\begin{array}{l}\text { The unreliability of storing data in one central } \\
\text { location }\end{array}$ & {$[52]$} & - implement data storage with multiple decentralized locations \\
\hline & $\begin{array}{l}\text { The financial feasibility regarding company } \\
\text { size }\end{array}$ & {$[52]$} & $\begin{array}{l}\text { - establish collaboration between multiple SMEs to divide the costs for implementing the BDA } \\
\text { technology } \\
\text { - collaborate between SMEs and academia to apply for international projects to implement the } \\
\text { BDA technology and obtain funding }\end{array}$ \\
\hline & $\begin{array}{l}\text { The unprofitable data kept in a limited storage } \\
\text { space }\end{array}$ & {$[52]$} & $\begin{array}{l}\text { - develop algorithms for preprocessing data, namely, for data modification and reduction in the } \\
\text { stored data size }\end{array}$ \\
\hline & Legislation challenges & {$[53]$} & $\begin{array}{l}\text { - adopt a new or change an existing company policy that will enable the implementation of new } \\
\text { technologies compliant with legislation changes }\end{array}$ \\
\hline & The lack of information system standards & [53] & - develop and implement standardized information systems \\
\hline & $\begin{array}{l}\text { The need for developing a backup } \\
\text { implementation plan }\end{array}$ & {$[53]$} & $\begin{array}{l}\text { - develop an implementation plan for the company that has "just in case" scenarios or an "exit } \\
\text { strategy" in case the company manufacturing performances are negatively impacted by } \\
\text { introducing BDA }\end{array}$ \\
\hline $\begin{array}{l}\text { Cloud } \\
\text { Computing }\end{array}$ & Insufficiently developed technology level & {$[55]$} & - further develop existing computing and communication technologies \\
\hline $\begin{array}{l}\text { Fog/Edge } \\
\text { Computing }\end{array}$ & $\begin{array}{l}\text { The lack of manufacturing system integration } \\
\text { using fog/edge computing technologies }\end{array}$ & {$[56]$} & $\begin{array}{l}\text { - integrate the existing manufacturing system before implementing fog and edge computing } \\
\text { technologies based on standardized protocols for system integration }\end{array}$ \\
\hline$A R / V R$ & $\begin{array}{l}\text { The lack of manufacturing system integration } \\
\text { using AR/VR technologies }\end{array}$ & {$[57]$} & $\begin{array}{l}\text { - implement AR/VR compatible devices that can collect and interpret data in the same way and } \\
\text { standardize protocols for fast and accurate data transfer }\end{array}$ \\
\hline \multirow[b]{2}{*}{$A M$} & The lack of skilled workers for AM processes & {$[58]$} & - provide training for workers in the AM technology \\
\hline & Excessive investments in $\mathrm{AM}$ equipment & {$[58]$} & $\begin{array}{l}\text { - develop less expensive AM technology } \\
\text { - collaborate between companies and academia to apply for international projects to reduce } \\
\text { investment costs in AM }\end{array}$ \\
\hline \multirow{2}{*}{ IoT, $A M$} & $\begin{array}{l}\text { The lack of manufacturing system integration } \\
\text { in the joint integration of IoT and } \mathrm{AM}\end{array}$ & [59] & - develop and implement standardized protocols \\
\hline & $\begin{array}{l}\text { The inability to produce mass-customized } \\
\text { products }\end{array}$ & [59] & $\begin{array}{l}\text { - design manufacturing systems to achieve higher flexibility } \\
\text { - further develop AM technology that can produce one-of-a-kind parts without setup times }\end{array}$ \\
\hline $\begin{array}{l}\text { IoT, BDA, } \\
\text { Robotics }\end{array}$ & $\begin{array}{l}\text { Legislation restrictions for robotics in the joint } \\
\text { integration of IoT, BDA and robotics }\end{array}$ & {$[60]$} & - develop legislation regarding artificial intelligence equipment implementation in companies \\
\hline $\begin{array}{l}\text { CPS, IoT, Cloud } \\
\text { Computing }\end{array}$ & $\begin{array}{l}\text { The lack of financial resources for the joint } \\
\text { implementation of the CPS, IoT and cloud } \\
\text { computing }\end{array}$ & {$[61]$} & $\begin{array}{l}\text { - establish collaboration between multiple SMEs to divide the costs for implementing CPS, IoT } \\
\text { and cloud computing technologies } \\
\text { - collaborate between SMEs and academia to apply for international projects to implement the } \\
\text { CPS, IoT and cloud computing technologies and obtain funding }\end{array}$ \\
\hline \multirow{2}{*}{$\begin{array}{l}\text { CPS, IoT, BDA, } \\
\text { Cloud } \\
\text { Computing }\end{array}$} & $\begin{array}{l}\text { Obstacles for data collection in the joint } \\
\text { implementation of CPS, IoT, BDA and cloud } \\
\text { computing }\end{array}$ & [39] & - invest in more reliable data collection devices and sensors \\
\hline & $\begin{array}{l}\text { The need for technology improvement in the } \\
\text { joint implementation of CPS, IoT, BDA and } \\
\text { cloud computing }\end{array}$ & [39] & $\begin{array}{l}\text { - develop more intelligent equipment that fulfills the requirements of the CPS, IoT, BDA and cloud } \\
\text { computing technologies implementation }\end{array}$ \\
\hline
\end{tabular}


them, code them, and derive opportunities to overcome them in the future. This goal was achieved through conducting an inductive systematic literature review of the Industry 4.0 literature (66 relevant articles). Notably, while the present research identified two types of Industry 4.0 implementation challenges (managerial and technological), aside from the general trends in Industry 4.0 implementation challenges, the focus of the research was on the identification and analysis of the managerial Industry 4.0 implementation challenges (addressed in 28 of 66 relevant articles). Moreover, two main groups of managerial Industry 4.0 implementation challenges were further identified and analyzed: managerial implementation challenges for overall Industry 4.0 implementation and managerial implementation challenges for Industry 4.0 defined technology category implementation.

As previously stated, the present research adds to the existing Industry 4.0 literature with the following contributions.

- Identified: relevant articles that report Industry 4.0 implementation challenges in the literature. To the best of our knowledge, the present research is the first to focus comprehensively on Industry 4.0 implementation challenges. This article provides a list of the 28 relevant articles (from 66) that reported managerial Industry 4.0 implementation challenges ( 28 relevant articles are listed in the introduction of the Results section-Footnote 1). We expect that the identification of these articles will be of interest to researchers dealing with Industry 4.0 implementation in the future.

- Identified main trends in Industry 4.0 implementation challenges reporting (see Section IV-A): In addition to identifying the main trends in the implementation challenges reporting, the future development of these trends was analyzed and discussed (see Section V-A).

- Classified Industry 4.0 implementation challenges into two main types: The inductive nature of the research led to classifying the implementation challenges into two types based on the issue they are addressing: managerial Industry 4.0 implementation challenges and technological Industry 4.0 implementation challenges. Notably, the focus of this article was limited to the managerial Industry 4.0 implementation challenges due to the need to focus the article.

- Identified and defined available managerial Industry 4.0 implementation challenges: After identifying all of the managerial Industry 4.0 implementation challenges, each challenge was subsequently defined. Altogether, 55 distinct challenges were identified, coded, and defined. Specifically, 23 implementation challenges were identified for Industry 4.0 overall implementation, and 32 implementation challenges were identified for defined Industry 4.0 technology category implementation. We expect that this work of identifying and coding the challenges and distilling their definitions will present a valuable resource and a reference for future research in Industry 4.0 implementation.

- Derived opportunities for overcoming managerial Industry 4.0 implementation challenges: The present research derived opportunities for overcoming each identified challenge. While we expect that identification, coding, and defining the managerial implementation challenges will be highly interesting to Industry 4.0 researchers, the derived opportunities for overcoming these challenges (see Table IV and Table V) take the present research one step further in contributing to the Industry 4.0 literature. Specifically, these opportunities provide a plethora of possibilities for new research endeavors as well as insights into possible future developments in Industry 4.0 implementation.

We recognize that the present research has its limits by focusing on only academic journals. We also recognize the importance of the large amount of material coming from industry conferences, technology workshops, industry-focused magazines, and other nonacademic sources. However, since, to the best of our knowledge, a survey on the implementation challenges does not exist in the literature, with the present research, we provide value to the community with the analysis of a significant amount of material from academic journals. In this way, the present research provides the first step by identifying the most significant challenges that designers and implementers need to have clear in mind to avoid large mistakes in the Industry 4.0 implementation. The analysis of the additional material (i.e., industry conferences, technology workshops, and industry-focused magazines) will add some valuable additional aspects. However, this will be a valuable addition addressed in future analyses.

As mentioned in the Introduction, the present research shows that there are two types of Industry 4.0 implementation challenges: managerial and technological. This article focuses only on the managerial challenges since this multifaceted area already has significant complexity. In future analyses, we will focus on technological Industry 4.0 implementation challenges.

\section{REFERENCES}

[1] B. Wang, "The future of manufacturing: A new perspective," Engineering, vol. 4, no. 5, pp. 722-728, 2018.

[2] S. S. Kamble, A. Gunasekaran, and S. A. Gawankar, "Sustainable industry 4.0 framework: A systematic literature review identifying the current trends and future perspectives," Process Saf. Environ. Protection, vol. 117 pp. 408-425, 2018.

[3] M. Ghobakhloo, "The future of manufacturing industry: A strategic roadmap," J. Manuf. Technol. Manage., vol. 29, no. 6, pp. 910-936, 2018.

[4] T. D. Oesterreich and F. Teuteberg, "Understanding the implications of digitisation and automation in the context of Industry 4.0: A triangulation approach and elements of a research agenda for the construction industry,' Comput. Ind., vol. 83, pp. 121-139, 2016.

[5] Z. Li, Y. Wang, and K. S. Wang, "Intelligent predictive maintenance for fault diagnosis and prognosis in machine centers: Industry 4.0 scenario," Adv. Manuf., vol. 5, no. 4, pp. 377-387, 2017.

[6] M. Piccarozzi, B. Aquilani, and C. Gatti, "Industry 4.0 in management studies: A systematic literature review," Sustainability, vol. 10, no. 10, pp. 1-24, 2018.

[7] D. Preuveneers, "The intelligent industry of the future: A survey on emerging trends, research challenges and opportunities in Industry 4.0," J. Ambient Intell. Smart Environ., vol. 9, no. 3, pp. 287-298, 2017.

[8] H. S. Kang et al., "Smart manufacturing: Past research, present findings, and future directions," Int. J. Precis. Eng. Manuf., Green Technol., vol. 3, no. 1, pp. 111-128, 2016.

[9] S. Wang, J. Wan, D. Li, and C. Zhang, "Implementing smart factory of Industrie 4.0: An outlook," Int. J. Distrib. Sens. Netw., vol. 12, pp. 1-10, 2016.

[10] Y. Lu, "Industry 4.0: A survey on technologies, applications and open research issues," J. Ind. Inf. Integr., vol. 6, pp. 1-10, 2017.

[11] M. Türkesş, I. Oncioiu, H. Aslam, A. Marin-Pantelescu, D. Topor, and S Căpuşneanu, "Drivers and barriers in using industry 4.0: A perspective of SMEs in Romania," Processes, vol. 7, no. 3, 2019, Art. no. 153. 
[12] B. Nikolic, J. Ignjatic, N. Suzic, B. Stevanov, and A. Rikalovic, "Predictive manufacturing systems in industry 4.0: Trends, benefits and challenges," in Proc. 28th DAAAM Int. Symp. Intell. Manuf. Autom., 2017, pp. 769-802.

[13] A. Moktadir, S. M. Ali, S. Kusi-sarpong, and A. A. Shaikh, "Assessing challenges for implementing Industry 4.0: Implications for process safety and environmental protection," Process Saf. Environ. Protection, vol. 117, pp. 730-741, 2018.

[14] A. Humayed, J. Lin, F. Li, and B. Luo, "Cyber-Physical systems security A survey," IEEE Internet Things J., vol. 4, no. 6, pp. 1802-1831, Dec. 2017.

[15] R. Y. Zhong, X. Xu, E. Klotz, and S. T. Newman, "Intelligent manufacturing in the context of industry 4.0: A review," Engineering, vol. 3, no. 5, pp. 616-630, 2017.

[16] L. Atzori, A. Iera, and G. Morabito, "The internet of things: A survey," Comput. Netw., vol. 54, no. 15, pp. 2787-2805, 2010.

[17] Y. Chen, H. Chen, A. Gorkhali, Y. Lu, Y. Ma, and L. Li, "Big data analytics and big data science: A survey," J. Manage. Anal., vol. 3, no. 1, pp. 1-42, 2016.

[18] S. Tiwari, H. M. Wee, and Y. Daryanto, "Big data analytics in supply chain management between 2010 and 2016: Insights to industries," Comput. Ind. Eng., vol. 115, pp. 319-330, 2018.

[19] P. Mell and T. Grance, The NIST Definition of Cloud Computing, Nat. Inst. Standards Technol., Inf. Technol. Lab., Gaithersburg, MD, USA, 2011 vol. 15, pp. 1-7.

[20] S. Khan, S. Parkinson, and Y. Qin, "Fog computing security: A review of current applications and security solutions," J. Cloud Comput., vol. 6, no. 1, 2017, Art. no. 19.

[21] W. Shi, J. Cao, Q. Zhang, Y. Li, and L. Xu, "Edge computing: Vision and challenges," IEEE Internet Things J., vol. 3, no. 5, pp. 637-646, Oct. 2016.

[22] K. Bilal, O. Khalid, A. Erbad, and S. U. Khan, "Potentials, trends, and prospects in edge technologies: Fog, cloudlet, mobile edge, and micro data centers," Comput. Netw., vol. 130, pp. 94-120, 2018.

[23] I. Odun-Ayo, R. Goddy-Worlu, V. Geteloma, and E. Grant, "A systematic mapping study of cloud, fog, and edge/mobile devices management, hierarchy models and business models," Adv. Sci. Technol. Eng. Syst. J., vol. 4, no. 2, pp. 91-101, 2019.

[24] A. M. Rahmani et al., "Exploiting smart e-health gateways at the edge of healthcare internet-of-things: A fog computing approach," Future Gener. Comput. Syst., vol. 78, pp. 641-658, 2018.

[25] S. Choi, K. Jung, and S. Do Noh, "Virtual reality applications in manufacturing industries: Past research, present findings, and future directions," Concurrent Eng. Res. Appl., vol. 23, no. 1, pp. 40-63, 2015.

[26] A. W. W. Yew, S. K. Ong, and A. Y. C. Nee, "Towards a griddable distributed manufacturing system with augmented reality interfaces," Robot. Comput. Integr. Manuf., vol. 39, pp. 43-55, 2016.

[27] A. Al-Fuqaha, "Internet of things: A survey on enabling technologies, protocols, and applications," IEEE Commun. Surv. Tut., vol. 1, no. 2, pp. 78-95, Oct.-Dec. 2013.

[28] A. L. Buczak and E. Guven, "A survey of data mining and machine learning methods for cyber security intrusion detection," IEEE Commun. Surv. Tut., vol. 18, no. 2, pp. 1153-1176, Apr./-Jun. 2016.

[29] A. Meroño-Peñuela et al., "Semantic technologies for historical research: A survey," Semantic Web, vol. 6, no. 6, pp. 539-564, 2014.

[30] V. Janev and S. Vraneš, "Applicability assessment of Semantic Web technologies," Inf. Process. Manage., vol. 47, no. 4, pp. 507-517, 2011.

[31] S. H. Huang, P. Liu, A. Mokasdar, and L. Hou, "Additive manufacturing and its societal impact: A literature review," Int. J. Adv. Manuf. Technol., vol. 67, nos. 5-8, pp. 1191-1203, 2013.

[32] M. K. Thompson et al., "Design for additive manufacturing: Trends, opportunities, considerations, and constraints," CIRP Ann. Manuf. Technol., vol. 65 , no. 2 , pp. 737-760, 2016.

[33] S. Ford and M. Despeisse, "Additive manufacturing and sustainability: An exploratory study of the advantages and challenges," J. Cleaner Prod. vol. 137, pp. 1573-1587, 2016.

[34] Standard Terminology for Additive Manufacturing Technologies, ASTM F2792-12a, 2013.

[35] N. Suzić, C. Forza, A. Trentin, and Z. Anišić, "Implementation guidelines for mass customization: Current characteristics and suggestions for improvement," Prod. Planning Control, vol. 29, no. 10, pp. 856-871, 2018.

[36] N. Suzić, E. Sandrin, S. Suzić, C. Forza, A. Trentin, and Z. Anišić, "Implementation guidelines for mass customization: A researcher-oriented view," Int. J. Ind. Eng. Manage., vol. 9, no. 4, pp. 229-243, 2018.

[37] S. Singh, B. Mahanty, and M. K. Tiwari, "Framework and modelling of inclusive manufacturing system," Int. J. Comput. Integr. Manuf., vol. 32, no. 2 , pp. $105-123,2018$.

[38] C. Chien, T. Hong, and H. Guo, "An empirical study for smart production for TFT-LCD to empower Industry 3.5," J. Chin. Inst. Eng., vol. 40, no. 7, pp. 552-561, 2017.
[39] B. Chen, J. Wan, L. Shu, P. Li, M. Mukherjee, and B. Yin, "Smart factory of industry 4.0: Key technologies, application case, and challenges," IEEE Access, vol. 6, pp. 6505-6519, 2018.

[40] D. R. Sjödin, V. Parida, M. Leksell, and A. Petrovic, "Smart factory implementation and process innovation: A preliminary maturity model for leveraging digitalization in manufacturing," Res. Technol. Manage., vol. 61 , no. 5, pp. 22-31, 2018.

[41] K. S. Kiangala and Z. Wang, "Initiating predictive maintenance for a conveyor motor in a bottling plant using industry 4.0 concepts," Int. J. Adv. Manuf. Technol., vol. 97, nos. 9-12, pp. 3251-3271, 2018.

[42] D. C. Fettermann, C. Gobbo, S. Cavalcante, D. De Almeida, and G. L. Tortorella, "How does Industry 4.0 contribute to operations management?," J. Ind. Prod. Eng., vol. 35, no. 4, pp. 255-268, 2018.

[43] G. L. Tortorella and D. Fettermann, "Implementation of industry 4.0 and lean production in brazilian manufacturing companies," Int. J. Prod. Res., vol. 56 , no. 8, pp. 2975-2987, 2018

[44] N. Agarwal and A. Brem, "Strategic business transformation through technology convergence: Implications from General Electric's industrial internet initiative," Int. J. Technol. Manag., vol. 67, nos. 2-4, pp. 196-214, 2015.

[45] D. Mourtzis, S. Fotia, N. Boli, and P. Pittaro, "Product-service system (PSS) complexity metrics within mass customization and Industry 4.0 environment," Int. J. Adv. Manuf. Technol., vol. 97, nos. 1-4, pp. 91-103, 2018.

[46] H. Zhang, Q. Liu, X. Chen, D. Zhang, and J. Leng, "A digital twin-based approach for designing and multi-objective optimization of hollow glass production line," IEEE Access, vol. 5, pp. 26901-26911, 2017.

[47] Z. Zhang, X. Wang, X. Wang, F. Cui, and H. Cheng, "A simulation-based approach for plant layout design and production planning," J. Ambient Intell. Humanized Comput., vol. 10, no. 3, pp. 1217-1230, 2018.

[48] F. Tao and M. Zhang, "Digital twin shop-floor: A new shop-floor paradigm towards smart manufacturing," IEEE Access, vol. 5, pp. 20418-20427, 2017

[49] K. Alexopoulos, S. Makris, V. Xanthakis, K. Sipsas, and G. Chryssolouris, "A concept for context-aware computing in manufacturing: The white goods case," Int. J. Comput. Integr. Manuf., vol. 29, no. 8, pp. 839-849, 2016.

[50] A. Theorin et al., "An event-driven manufacturing information system architecture for Industry 4.0," Int. J. Prod. Res., vol. 55, no. 5, pp. 1297-1311, 2017.

[51] Y. Xu and M. Chen, "An Internet of Things based framework to enhance just-in-time manufacturing," Proc. Inst. Mech. Eng. Part B, J. Eng. Manuf., vol. 232, no. 13, pp. 2353-2363, 2018.

[52] J. Lenz, T. Wuest, and E. Westkämper, "Holistic approach to machine tool data analytics," J. Manuf. Syst., vol. 48, pp. 180-191, 2018.

[53] P. O'Donovan, K. Leahy, K. Bruton, and D. T. J. O'Sullivan, “An industrial big data pipeline for data-driven analytics maintenance applications in large-scale smart manufacturing facilities," J. Big Data, vol. 2, no. 1, pp. 1-26, 2015

[54] J. Wan et al., "A manufacturing Big data solution for active preventive maintenance," IEEE Trans. Ind. Informat., vol. 13, no. 4, pp. 2039-2047, Aug. 2017.

[55] S. Wang, C. Zhang, C. Liu, D. Li, and H. Tang, "Cloud-assisted interaction and negotiation of industrial robots for the smart factory R," Comput. Elect. Eng., vol. 63, pp. 66-78, 2017.

[56] P. Lalanda, D. Morand, and S. Chollet, "Autonomic mediation middleware for smart manufacturing," IEEE Internet Comput., vol. 21, no. 1, pp. 32-39, Jan./Feb. 2017.

[57] F. Longo, L. Nicoletti, and A. Padovano, "Smart operators in industry 4.0: A human-centered approach to enhance operators' capabilities and competencies within the new smart factory context," Comput. Ind. Eng., vol. 113, pp. 144-159, 2017.

[58] F. Murmura and L. Bravi, "Additive manufacturing in the wood-furniture sector: Sustainability of the technology, benefits and limitations of adoption," J. Manuf. Technol. Manage., vol. 29, no. 2, pp. 350-371, 2018.

[59] L. F. C. S. Durão, A. Christ, E. Zancul, R. Anderl, and K. Schützer, "Additive manufacturing scenarios for distributed production of spare parts," Int. J. Adv. Manuf. Technol., vol. 93, nos. 1-4, pp. 869-880, 2017.

[60] V. Gružauskas, S. Baskutis, and V. Navickas, "Minimizing the trade-off between sustainability and cost effective performance by using autonomous vehicles," J. Cleaner Prod., vol. 184, pp. 709-717, 2018.

[61] D. Mourtzis and E. Vlachou, "A cloud-based cyber-physical system for adaptive shop-floor scheduling and condition-based maintenance," $J$. Manuf. Syst., vol. 47, pp. 179-198, 2018.

[62] Gartner Inc. "Garter," 2018. [Online]. Available: https://www.gartner. com/en/research/methodologies/gartner-hype-cycle, Accessed on: Apr. $5,2019$. 